\title{
Affect and Job Satisfaction: A Study of Their Relationship at Work and at Home
}

\author{
Timothy A. Judge \\ University of Florida
}

\author{
Remus Ilies \\ Michigan State University
}

\begin{abstract}
The authors investigated 2 broad issues: (a) across- and within-individual relationships between mood and job satisfaction and (b) spillover in moods experienced at work and at home. Using an experiencesampling methodology, they collected multisource data from a sample of 74 working individuals. Multilevel results revealed that job satisfaction affected positive mood after work and that the spillover of job satisfaction onto positive and negative mood was stronger for employees high in trait-positive and trait-negative affectivity, respectively. Results also revealed that the effect of mood at work on job satisfaction weakened as the time interval between the measurements increased. Finally, positive (negative) moods at work affected positive (negative) moods experienced later at home.
\end{abstract}

Kuhn (1970) argued that much scientific progress is not the result of a steady accumulation of knowledge. Rather, scientific revolutions take place in which one paradigm is replaced by another. Although it might be hyperbole to argue that a revolution is underway in job attitudes research, it can be argued that a paradigm shift is afoot. Researchers have long accepted Locke's (1969) classic definition of job satisfaction, which incorporates both cognitive ("an appraisal of one's job" [p. 317]) and affective ("emotional state" [p. 317]) elements. From the perspective of basic attitude research, this acceptance is well-founded given the classic separation of attitudes into cognitive, affective, and behavioral dimensions (Eagley \& Chaiken, 1993).

A great deal of work on the antecedents of job satisfaction has focused on relatively cognitive models. Locke's (1969) valuepercept model, for example, involves a rational appraisal of the degree to which the job supplies outcomes that satisfy an individual's values. The Cornell model involves a comparison of job outcomes with job inputs, conditioned by an individual's frame of reference (Hulin, 1991). Similarly, a considerable amount of research has linked job satisfaction to various behaviors (Spector, 1997), and numerous meta-analyses summarizing results of studies linking job satisfaction to outcomes such as job performance, absenteeism, turnover, and citizenship behaviors have been published. Thus, the cognitive and behavioral aspects of job satisfaction are relatively better developed than its affective dimension in past research.

Given the relative underemphasis on affect, then, the source and nature of the paradigm shift, or "fresh approach" (Brief, 1998, p. $85)$, is on the affective side. The researchers who can be most directly credited with fomenting this realignment are $\mathrm{H}$. Weiss and A. Brief. Weiss (2002), after reviewing current thinking in the

Timothy A. Judge, Department of Management, University of Florida; Remus Ilies, Department of Management, Michigan State University.

Correspondence concerning this article should be addressed to Timothy A. Judge, Department of Management, 211D Stuzin Hall, University of Florida, Gainesville, FL 32611. E-mail: timothy.judge@cba.ufl.edu attitudes literature, argued that affect and cognition are distinct influences on (rather than dimensions of) job satisfaction and further contended that affective influences have been neglected. Spector (1997) appears to agree with Weiss, commenting, "Today most researchers tend to focus attention on cognitive processes" ( $p$. 2). Brief (1998) also argued that the cognitive perspective has dominated job satisfaction research and focuses in particular on measurement approaches. In appraising current measures of job satisfaction, Brief concluded, "Organizational scientists often have been tapping the cognitive dimension while slighting or even excluding the affective one" (p. 87).

The importance of this shift in focus is twofold. First, although cognitive models of job satisfaction such as Locke's (1969) valuepercept theory have a certain level of validity, they do not explain a majority of the variance in job satisfaction. Similarly, the dispositional sources of job satisfaction, although important, likewise do not fully explain individual differences in job satisfaction (Ilies \& Judge, 2002) and do little to "enlighten the underlying process" (Weiss \& Cropanzano, 1996, p. 9). Second, because much of the temporal variation in job satisfaction may therefore be due to variation in mood or affect (Fisher, 2002), studying the affective foundations of job satisfaction may allow us to better predict and understand job satisfaction as it is experienced by individuals. Thus, in addition to explaining variation in job satisfaction across individuals, the study of affect in job satisfaction research holds the promise of explaining within-individual variation in job satisfaction that would otherwise be missed. Brief and Weiss (2002) noted, "Whereas it is clear that temperaments can influence job satisfaction, the processes by which this happens are not yet well understood" (p. 286). These authors note that considering dynamic affective states in job satisfaction research holds the promise of elucidating both within- and across-individual variations in job satisfaction.

Because of the newness of the perspective, the realignment that these authors project has not yet been realized. However, there have been several studies published that provide support for the importance of affect in job satisfaction. The vast majority of this 
affect-oriented research has concerned the link between trait affectivity and job satisfaction (e.g., Watson \& Slack, 1993). Metaanalytic evidence indicates that both trait-positive affectivity (PA) and trait-negative affectivity (NA) are related to job satisfaction, with trait PA somewhat more strongly so (Connolly \& Viswesvaran, 2000). As opposed to trait affect, two recent studies have investigated the effect of state affect or mood on job satisfaction using dynamic designs. Weiss, Nicholas, and Daus (1999) used experience-sampling methodology, in which managers' mood levels were sampled four times a day to investigate the relationship of affective experiences to job satisfaction. Weiss et al. (1999) found that both mood at work and job cognitions contribute to job satisfaction. Ilies and Judge (2002), in the first study that measured job satisfaction with a state approach (multiple time-sampled momentary measurements), found that mood and job satisfaction were related both within and across individuals and further found that within-individual variance comprised $36 \%$ of the total variance in job satisfaction. This is variance that would be missed with the typical between-subjects design.

Mindful of the contributions of these studies, much remains to be done. Specifically, with few exceptions (Fisher, 2002; Ilies \& Judge, 2002; Weiss et al., 1999), there is a dearth of published job attitudes research that has used a dynamic design. Typically, most research uses a cross-sectional design in which a single-shot measure of affect is related to a similar measure of job satisfaction. Though there is nothing inherently wrong with such designs, they do assume that both mood and job satisfaction are stable constructs and therefore any temporal variation is consigned to measurement error. Yet we know that both mood and job satisfaction are constructs that exhibit substantial short-term variation (Ilies \& Judge, 2002; Weiss et al., 1999). Thus, if researchers are to better understand the affective nature of job satisfaction, they must use a dynamic design that allows them to capture and explain the temporal variation in both constructs.

Another important issue is whether individuals who experience the most or the least positive affective states at work also experience similar levels of affect off work, relative to others. George (1989), in her study on mood and absence, suggested that "Not only should we consider how workers feel at work, but also how they feel off the job" (p. 321). Moreover, the potential spillover effects (Lambert, 1990) from work to home or from home to work should not be confined to mood. Specifically, because job satisfaction can be viewed as both affective in nature and with affective influences (Brief \& Weiss, 2002), it is relevant to investigate the degree to which job satisfaction experienced at work influences mood away from work. Edwards and Rothbard (2000) noted that one of the primary ways in which work and family spillover effects occur is in terms of affect or mood. They noted, "Mood spillover occurs when mood in one domain affects mood in the other domain" (Edwards \& Rothbard, 2000, p. 185).

However, as Edwards and Rothbard (2000) noted, little empirical research has addressed the nature of these spillover effects despite the potential implications for well-being and performance in work and family roles. Indeed, although potential spillover effects have been investigated in both the job-life satisfaction literature (Wright, Bennett, \& Dun, 1999) and the work-family literature (Sumer \& Knight, 2001), we are not aware of any studies that have investigated these types of spillover effects with respect to mood and job satisfaction at work and at home. In general, the work-family literature is dominated by an assumption that work and family roles conflict, when possible spillover effects have been systematically investigated (Parasuraman \& Greenhaus, 2002). It seems likely that one mechanism that contributes to work-family spillover is the emotional states experienced in both domains (Rothbard, 2001). Thus, one way to enhance understanding of the permeabilities of work and family domains is to study the emotional experiences in both domains. If mood at work and mood at home are related, this would provide new evidence regarding the spillover effects in the two roles.

Accordingly, the present study has two broad purposes. First, we investigated the influence of mood dimensions on job satisfaction, and we explored the interrelationship between mood experienced both at work and at home and job satisfaction at work. Second, we examined the relationships between mood at work and mood at home, focusing on spillover effects from work to home. In the next section of the article, we link dimensions of mood to job satisfaction, both across individuals and dynamically, and consider mood both at work and at home.

\section{Hypotheses}

A great deal of research has related measures of trait affectivity to job satisfaction. Brief and Weiss (2002) commented, "Detected relationships between negative and/or positive affectivity and job satisfaction now are commonplace in the literature" (p. 284). However, the processes by which trait affectivity results in job satisfaction are still not entirely clear (Brief, 1998; Brief \& Weiss, 2002). Brief's (1998) model in general, and Brief and Weiss's comments in particular, suggest that mood at work explains, in part, the relationship between trait affectivity and job satisfaction. As Brief and Weiss noted, "Temperaments influence job satisfaction through both mood at work and interpretations of job circumstances" (p. 285). Indeed, Weiss (2002) presented evidence that mood mediates more of the effect of affective temperament on job satisfaction than do cognitive beliefs. Although Fisher (2002) did not test this mediated relationship, her results support it in that state affect was more strongly correlated with job satisfaction than was trait affect. Given the logical nature of the relationship, and some supporting evidence, it is surprising that direct tests of this mediated relationship have been lacking in the literature. As Fox and Spector (2002) noted, although personality research has shown that there is validity to personality, "It is not clear to what extent findings are mediated by the actual experience of emotions" ( $p$. 168).

In theory, that state affect (mood) will be a more proximal influence on job satisfaction than trait affect (affectivity) is consistent with construct correspondence arguments (Fishbein \& Ajzen, 1975). Specifically, both mood and job satisfaction are psychological states that are influenced by traits but exhibit substantial short-term variability (Ilies \& Judge, 2002). In this way, mood and job satisfaction correspond more closely than do affectivity and job satisfaction. However, this correspondence can only be realized and investigated when mood and job satisfaction are analyzed dynamically so that their temporal covariation can be assessed.

Hypothesis 1: Across individuals, positive and negative mood at work will mediate the effect of trait PA and trait NA on job satisfaction. 
Several recent studies have documented relationships between mood and job satisfaction in dynamic designs (Fisher, 2002; Ilies \& Judge, 2002; Weiss et al., 1999). Although affect and cognition are closely - in many ways inseparably-intertwined (Damasio, 2001), emotions are quite ephemeral in nature (Izard, 1991). At the same time, there is the process of emotional generalization in which domain-specific or general emotions spill over onto those experienced in another domain (in this case, the job domain). It is this emotional generalization that explains why mood and job satisfaction are linked when assessed in close correspondence but that over time, the effects weaken as the time interval between the measurements increases.

Although the few dynamic studies that have been published suggest that mood is related to job satisfaction, these studies have not been able to investigate whether validities generalize over time or across contexts. Although there is no research directly on point here, research from related areas suggests that the effect of mood at work on job satisfaction will be strongest when job satisfaction is assessed at the same time as is mood and weaker when measurement of these concepts is separated. Research suggests that predictive validities decline as the predictor and criterion become more temporally remote (Hulin, Henry, \& Noon, 1990). Moreover, the mood congruency hypothesis (Rusting \& DeHart, 2000), whereas supporting a link between affective experiences in different domains, also suggests that these linkages weaken over time. Memories decay, some rather quickly (Altmann \& Gray, 2002), and as memories decay, the moods carried with them should fade as well. Collectively, these arguments support the expectation that momentary mood will affect job satisfaction the strongest when the two concepts are assessed contemporaneously, but the effect of mood at work on job satisfaction will grow weaker as job satisfaction is measured at a time increasingly distant from the measure of mood.

Hypothesis 2: Within individuals, momentary mood will predict concurrent job satisfaction such that (a) positive mood will have a positive effect on job satisfaction and (b) negative mood will have a negative effect on job satisfaction.

Hypothesis 3: The within-individual effect of mood at work on job satisfaction will grow weaker as the time interval increases.

Though most researchers in organizational psychology are more likely to view mood as an independent variable, this certainly need not be the case. Furthermore, the influences on positive and negative affect are generally quite different. Watson (2000) discusses that negative events such as stress are more likely to influence negative mood whereas positive events such as social interaction are more likely to impact positive mood. He noted, "Negative mood increases in response to various types of unpleasant events and aversive stimuli, whereas. . positive mood states are much more responsive to pleasant events" (Watson, 2000, p. $63)$. For most, work is both a source of identity and a source of purpose in life (Hulin, 2002). Furthermore, as Hulin (2002) noted, the distinction between work and nonwork is increasingly fuzzy. As a result of the increasing permeability of work and nonwork boundaries, one would expect feelings about one's job to spill over onto one's mood away from work. Because job satisfaction is a positive psychological state (Locke, 1976), we expect job satisfaction to spill over onto positive mood more so than onto negative mood.

Rothbard's (2001) engagement hypothesis suggests that positive emotions experienced at work spill over onto the emotions experienced at home. One aspect of this engagement hypothesis is that engagement at work (work attention and absorption) is positively associated with positive mood at home. As noted by Rothbard, supporting this expectation is the argument that individuals who have high levels of job satisfaction do not bring their troubles home with them and therefore come home in a more positive frame of mind and are more receptive to their family. Although Rothbard's results did not support this aspect of the engagement hypothesis, her measure of work engagement focused more on cognitive processes (e.g., time spent thinking about work, concentration applied to work, absorption in work) than emotional reactions to work. Thus, it is reasonable to hypothesize greater spillover from work-role affect (job satisfaction) to positive mood at home than would be the case with work engagement.

Hypothesis 4: Within individuals, job satisfaction at work will have (a) a positive effect on positive mood after work and (b) a negative effect on negative mood after work.

An accumulating body of research suggests that individuals' personalities influence their susceptibility to positive and negative stimuli such that extraverted individuals are more affected by rewards and positive events and neurotic individuals are more affected by punishments and negative events (see Stewart, 1996). Indeed, theory and empirical evidence suggest that when in a positive mood, positively disposed individuals (extraverts) have more positive memories (than less positive individuals), and when in a negative mood, negatively disposed individuals (neurotic individuals) have more negative memories (than less negative individuals; \& Larsen, 1999). Thus, how individuals regulate their moods is based in part on their dispositional orientations, with extraverts having their positive moods more easily affected by positive events and neurotic individuals having their negative moods more easily affected by negative events. For example, in Larsen and Ketelaar's (1989) study, pleasant and unpleasant moods were induced using false performance feedback (success and failure respectively). PA and NA were assessed both before and after the mood induction. Extraversion predicted significant increases in PA to the success feedback, and neuroticism predicted significant increases in NA to the failure feedback. Such individual differences in receptivity to stimuli or moods are consistent with Gray's (1990) reinforcement sensitivity theory, which argues that extraverts are mainly motivated by pleasure or reward and therefore have a strong tendency to approach, whereas neurotic individuals are mainly motivated to avoid punishment and therefore have a strong tendency to inhibit their behavior.

In testing reinforcement sensitivity theory with respect to mood, one can use trait PA and trait NA to assess the sensitivity to positive and negative stimuli in that researchers tend to equate trait PA with extraversion and trait NA with neuroticism (Brief, 1998; Watson, 2000). Indeed, Watson, Wiese, Vaidya, and Tellegen (1999) viewed trait PA and trait NA as indicators of the responsiveness to positive and negative stimuli, respectively. If job satisfaction can be seen as an "arousal mechanism" (Matthews \& 
Gilliland, 1999) that stimulates positive emotional reactions, one would then expect those high on trait PA to be more affected by job satisfaction and those high on trait NA to be more affected by job dissatisfaction.

Hypothesis 5: The within-individual effect of job satisfaction on positive mood after work will be moderated by trait PA (Hypothesis 5a) and the effect of job satisfaction on negative mood after work will be moderated by trait NA (Hypothesis $5 b$ ) such that the relationships are stronger for those with high trait PA and high trait NA, respectively.

One issue for which research is conspicuously absent is the relationship between mood at work and mood away from work. George (1989) suggested that researchers should consider both mood at work and mood off the job. Although Rothbard (2001) did not examine the dynamic relationship between mood at work and mood at home (hers was a between-subjects, cross-sectional design), several arguments she used to support the engagement hypothesis also support the relationship between positive mood at work and at home. Specifically, because positive mood is related to prosocial actions toward others (Isen \& Baron, 1991) and helping others enhances one's own mood (Williamson \& Clark, 1989), individuals who are in a good mood at work should engage in both thoughts and actions that make it more likely (compared with individuals in a less positive mood) to carry this positive affect home with them.

We further expect that positive mood at home will be more affected by positive mood at work than by negative mood at work, with the reverse also holding true with respect to negative mood at work and at home. One of the more enduring findings in the mood literature is a correlational hierarchy of affects such that discrete positive emotions correlate highly with one another and discrete negative emotions correlate highly with one another, but positive and negative emotions are either uncorrelated or somewhat weakly correlated with each another (Watson, 2000). Thus, positive (negative) emotions correlate more highly with other positive (negative) emotions than they do with each other. The relationship between state mood and trait mood appears to follow this same positive-to-positive and negative-to-negative pattern. For example, in Fisher (2002), trait-positive mood was significantly correlated with state-positive mood $(r=.60, p<.01)$ but was uncorrelated with state-negative mood $(r=.00, n s)$, whereas trait negative mood was more strongly correlated with state negative mood $(r=$ $.34, p<.05)$ than with state positive mood $(r=-.14, n s)$.

The positive-to-positive and negative-to-negative correlational pattern is consistent with the mood congruency hypothesis in personality psychology. The mood congruency hypothesis argues that positive moods elicit positive interpretations of events and pleasant thoughts and feelings, whereas negative moods bring about the opposite reactions (Rusting \& DeHart, 2000). Because the mood congruency hypothesis is based on associative models of memory, in which earlier moods lead to congruent later moods through mood-based memories (Bower, 1981), positive mood at work should set in motion a self-fulfilling prophecy in which individuals process subsequent information in such a way as to reinforce their original positive mood. The same should be true of negative moods at work. Thus, although the relationship between mood at work and mood at home has not been investigated, both the correlational hierarchy and the mood congruency hypothesis suggest particular links between positive moods at work and at home and negative moods at work and at home.

Hypothesis 6: Within individuals, positive mood at work will have a positive effect on positive mood at home (Hypothesis $6 a$ ) and negative mood at work will have a positive effect on negative mood at home (Hypothesis 6b).

One may wonder how our arguments preceding Hypothesis 6 - that moods experienced at work spill over onto moods at home later the same day-conform with Hypothesis 2, which postulated that the effects of mood on job satisfaction weaken as the time interval of measurement increases. These hypotheses are not in opposition to one another for several reasons. First, the generalization of moods earlier in the day to moods later in the day is different from the generalization of moods in one day to job satisfaction assessed later in the day or on the next day in that the generalization in the latter crosses two bridges (a time interval and different concepts [mood and job satisfaction]). Second, moods are ephemeral, but they are not as fleeting as are emotions, the experience of which dissipates almost immediately (Izard, 1991; Watson, 2000). Thus, whereas the influence of moods can be expected to dissipate on subsequent affective states over time, unlike emotions such as anger or fear, this dissipation is not expected to be immediate.

\section{Method}

\section{Participants}

Participants were 74 university employees from a southeastern state. These individuals were selected through an e-mail letter soliciting participation that was sent to a random sample of the employees listed in the university e-mail directory. The sample included personnel with typical administrative positions such as secretary or office manager. Participation in the study was completely voluntary; the employees who completed the study received a small honorarium for their participation.

\section{Procedure}

We collected the following three types of data: reports of mood and job satisfaction at work, reports of mood away from work, and measures of trait affectivity. To obtain mood and job satisfaction reports, we used experience-sampling methodology (Wheeler \& Reis, 1991). To measure trait affectivity, we used ratings provided by significant others (e.g., spouse, family member, close friend). We obtained trait affectivity ratings for 55 participants.

To measure mood and job satisfaction at work, we used intervalcontingent experience-sampling methodology, asking employees to report their momentary mood and job satisfaction three times a day for 2 weeks. These data were collected through an Internet interface. Subjects logged on to a Web page and were first presented with a job satisfaction survey. On completion of the job satisfaction survey, participants completed an adjective-based mood survey. The order in which the mood adjectives appeared in the survey was randomized across occasions. Participants were asked to complete on-line surveys at 9:00 a.m., 12:00 p.m., and 3:00 p.m. on each working day of the study, and the electronic interface was programmed to accept the data for each designated time only once within a 2-hr window and to record the exact time of data submission (e.g., the 9:00 a.m. survey was accepted between 8:00 a.m. and 10:00 a.m.). 
On each working day of the study, participants also were required to complete a survey that included mood measures from an off-work location (e.g., home) in the evening. Participants were instructed to complete the off-work surveys at 7:00 p.m.. On nonworking days (e.g., weekend days), two off-work surveys were required, one at 11:00 a.m. and one at 7:00 p.m. Participants had two options for completing the off-work surveys: They could use an Internet survey similar to the one used to collect the work data, or they could complete the same questionnaire on paper surveys that were mailed to those who indicated they preferred this option.

For the participants for whom we have complete data sets (55 individuals), we computed the response rates for experience-sampling ratings as follows. These respondents provided 1,204 experience-sampling ratings from work, which is equivalent to an overall response rate of $81 \%$ (the maximum number of ratings was 9 [days] $\times 3$ [surveys per day] $\times 55$ [participants] $=1,485$; the response rate was computed by comparing the number of ratings that we received $[1,204]$ with the maximum number of possible ratings [1,485]). Participants provided 715 off-work ratings, of which 395 were submitted electronically, and 320 were entered on paper surveys. The overall response rate for off-work surveys was $68 \%$ (as with the work ratings, the response rate was based on the maximum number of ratings for the 55 participants)

\section{Measures}

Mood. Mood was assessed with an adjective-based survey. We used the Positive and Negative Affect Schedule (Watson, Clark, \& Tellegen, 1988) to measure the broad factors of positive and negative affect (both positive and negative affect were measured with 10 adjectives). Instructions asked respondents to enter a number ranging from 0 (not at all) to 6 (extremely much) in the fields adjacent to each adjective to estimate the extent to which the adjective described their momentary mood. The same survey was used to measure both work and off-work mood. For the work data, the internal consistencies of the positive and negative affect (mood) scales, computed on individuals' mean ratings, were .97 and .94 , respectively. The internal consistency of the off-work scores was .97 for positive mood and .95 for negative mood.

Job satisfaction. Job satisfaction was measured with a five-item version of the Brayfield and Rothe (1951) measure. The scale was administered with momentary time instructions (e.g., "Right now, each minute of work seems like it will never end," "At this very moment I am fairly satisfied with my job," and "Right now, I find real enjoyment in my work"), and ratings were obtained on a 5-point scale ranging from 1 (strongly disagree) to 5 (strongly agree). The internal consistency of the scores, computed on mean item ratings, was .95 .

Trait PA and trait NA. We used the Positive and Negative Affect Schedule (Watson, Clark, \& Tellegen, 1988), with general instructions, to measure trait PA and trait NA (as with the mood scales, each affectivity scale was measured with 10 items). As noted, we received significant-other ratings of these personality factors for 55 participants. Internal consistency was .91 for trait PA and .88 for trait NA (in the case of other ratings, an alternative index of reliability is interrater agreement; because only one person provided other ratings, we were unable to compute such an index).

\section{Analyses}

We used two types of analyses: To test the hypothesis on the role of mood in mediating the effect of individual differences in trait affectivity on job satisfaction (Hypothesis 1), we used ordinary least squares regression analysis. To model within-individual and cross-level effects, we used hierarchical linear modeling (HLM). For the ordinary least squares regression analyses, we used the average (across all occasions) responses of all 55 participants with complete significant-other ratings. For multilevel analyses we used the data provided by 74 individuals for momentary within-individual analyses and used the data sets of individuals for whom we also had significant other personality ratings (55 respondents) to investigate cross-level effects. ${ }^{1}$

To test the hypotheses concerning dynamic relationships with multilevel analyses, we used either momentary experience-sampling ratings (for Hypothesis 2 [mood influences concurrent job satisfaction] and Hypothesis 3 [the effect of momentary mood on job satisfaction diminishes as the time interval increases]) or averaged experience-sampling responses for each participant and each day (daily ratings; for the hypotheses concerning satisfaction and mood spillover effects [Hypothesis 4 and Hypothesis 6] and moderating influences [Hypothesis 5]). We decided to use daily averages for testing spillover effects and moderating influences because using momentary ratings would have made the analyses unnecessarily complex (either presenting three sets of analyses or regressing the home mood on work variables measured at three distinct times) and would have decreased the number of individual data points available for the analyses (analyses at the daily level use the data for individuals who missed one or two assessments in a specific day). ${ }^{2}$ For both momentary and daily analyses, we used HLM (Byrk \& Raudenbush, 1992). HLM uses a two-stage iterative approach to estimate the relationships among variables at two levels of analysis. To estimate the effect of job satisfaction on off-work mood, for example, at the first level of analysis (Level 1), off-work mood is regressed on job satisfaction for each individual in the study. If no predictors are included at Level 2, then individuals' Level 1 intercepts and slopes are regressed onto a unit vector, which actually estimates the pooled effect of job satisfaction on off-work mood. If the Level 1 intercepts and slopes are regressed on between-subjects variables (trait affectivity), the Level 2 results test the moderator effect of trait affectivity on the job satisfaction-home mood relationship. We used HLM 5 (Byrk, Raudenbush, \& Congdon, 2000) to test the hierarchical models.

\section{Results}

Means and intercorrelations (computed across subjects) are presented in Table 1. The table also presents standard deviations computed between individuals, within individuals on the basis of momentary scores, and within individuals on the basis of daily average scores (where appropriate).

\section{Between-Individual Analyses}

Hypothesis 1 posited that across individuals, positive and negative mood at work would mediate the effect of trait PA and trait NA on job satisfaction. To test this hypothesis, we performed several hierarchical regressions. In the first block, we entered trait PA and trait NA. As shown in Table 2, trait PA significantly predicted job satisfaction but trait NA did not. In the second block, average state measures of positive and negative mood were entered into the regression predicting job satisfaction. As the table shows, both state affects - positive and negative-significantly predicted job satisfaction. It is interesting that trait PA remained a significant

\footnotetext{
${ }^{1}$ The total number of momentary observations used for withinindividual analyses varied according to which variables were included in the specific analyses (because of listwise deletion).

${ }^{2}$ For analyses that predicted job satisfaction on the basis of momentary data, we included a lagged job satisfaction variable to account for serial dependence in job satisfaction ratings (Ilies \& Judge, 2002). Including lagged satisfaction in the within-individual models reduced the total number of observations because we did not lag across nonconsecutive obser vations (these were treated as missing data). Because using the daily responses eliminated the problem of autocorrelation, we did not include lagged predictors as control variables in these analyses.
} 
Table 1

Means, Standard Deviations, and Intercorrelations Across Individuals for All Study Variables

\begin{tabular}{|c|c|c|c|c|c|c|c|c|c|c|c|}
\hline Variable & $M$ & $S D_{\mathrm{b}}$ & $S D_{\mathrm{wm}}$ & $S D_{\mathrm{wd}}$ & 1 & 2 & 3 & 4 & 5 & 6 & 7 \\
\hline 1. Trait-positive affectivity & 48.80 & 11.19 & & & - & & & & & & \\
\hline 2. Trait-negative affectivity & 23.23 & 9.97 & & & -.16 & - & & & & & \\
\hline 3. Average state positive mood at work & 27.30 & 12.52 & 8.14 & 6.98 & .11 & -.06 & - & & & & \\
\hline 4. Average state negative mood at work & 4.74 & 6.76 & 4.52 & 4.19 & -.11 & .00 & .11 & - & & & \\
\hline 5. Average state positive mood at home & 23.68 & 13.42 & & 8.63 & .01 & .10 & $.85^{* *}$ & .18 & - & & \\
\hline 6. Average state negative mood at home & 4.32 & 7.12 & & 5.09 & -.03 & -.03 & .10 & $.93 * *$ & .13 & - & \\
\hline 7. Average state job satisfaction & 17.67 & 3.73 & 2.73 & 2.28 & $.35 * *$ & -.16 & $.49^{* *}$ & $-.46^{* * *}$ & $.27 *$ & $-.40 * *$ & - \\
\hline
\end{tabular}

Note. $\quad N \mathrm{~s}=55-74$. Trait-positive and trait-negative affectivity were measured with significant other ratings. $S D_{\mathrm{b}}=$ standard deviation computed between individuals; $S D_{\mathrm{wm}}=$ within-individual standard deviation of momentary scores; $S D_{\mathrm{wd}}=$ within-individual standard deviation of daily averages.

$* p<.05 . \quad * * p<.01$.

predictor of job satisfaction controlling for mood (the two state affects). Thus, Hypothesis 1 was supported, but only partially. Though mood did explain part of the effect of trait PA on job satisfaction, it did so only in part. These results should be interpreted with caution because of the relatively low power given the small sample size.

\section{Momentary Within-Individual Analyses}

The second hypothesis (Hypothesis 2) predicted that within individuals and across time, mood at work would have an effect on concurrent job satisfaction. To test this hypothesis we estimated a model (Model 1) that at Level 1 regressed momentary job satisfaction on positive and negative mood (the affect scores were centered at the individuals' means to eliminate between-individual variances in these scores), and it estimated the pooled value of the within-individual predictors at Level 2 (i.e., no Level 2 predictors were included in this model). ${ }^{3}$ The equations for this model are shown in the Appendix; Table 3 presents the results. As these results show, the hypothesis received strong support in that both positive mood (standardized $\beta=.45, p<.01$ ) and negative mood (standardized $\beta=-.40, p<.01$ ) were strong predictors of concurrent job satisfaction. ${ }^{4}$

Table 2

Mediating Effect of Mood at Work on the Trait Affectivity-Job Satisfaction Relationship

\begin{tabular}{lcc}
\hline \multicolumn{1}{c}{ Variable } & $\beta$ & $R^{2}$ \\
\hline Step 1: trait affectivity & & \\
Trait-positive affectivity & $.34^{* *}$ & \\
Trait-negative affectivity & -.09 & \\
$R^{2}$ & & $.14^{*}$ \\
Step 2: trait affectivity + mood at work & $.25^{* *}$ & \\
Trait-positive affectivity & -.07 & \\
Trait-negative affectivity & $.58^{* *}$ & \\
Positive mood at work & $-.31^{* *}$ & \\
Negative mood at work & & $.45^{* *}$ \\
$\Delta R^{2}$ & & $.59^{* *}$ \\
$R^{2}$ & & \\
\hline
\end{tabular}

Note. $N=55$. Trait-positive and trait-negative affectivity were measured with significant-other ratings.

$* p<.05$. ** $p<.01$.
Hypothesis 3 predicted that the effect of mood at work on job satisfaction would weaken as the time interval between the measurement of mood and job satisfaction increased. To test this hypothesis, we compared the effects of momentary mood on concurrent momentary job satisfaction (time $t$; this model is identical to Model 1 described above) with the effects of momentary mood on momentary job satisfaction assessed after one time period (time $t+1$ ), two time periods (time $t+2$ ) or in the morning of the next day. The results in Table 4 reveal that when both mood and job satisfaction were assessed concurrently at work, both positive and negative mood significantly predicted job satisfaction. At time $t+1$, only negative mood remained a significant predictor of job satisfaction, and at time $t+2$, the effect of mood on job satisfaction virtually disappeared. (The Model 1 equations are shown in the Appendix; the equations for the models predicting job satisfaction at time $t+1$ and time $t+2$, or next day, are similar to those for Model 1). This pattern of results suggests support for Hypothesis 3.

\section{Daily Within-Individual Analyses}

Hypothesis 4 predicted that job satisfaction at work would affect both positive and negative mood after work. To test the first part of this hypothesis (Hypothesis 4a), we specified an HLM model in which at Level 1, positive mood after work was regressed on job satisfaction at work (Model 2). Job satisfaction scores were centered relative to individuals' means, thus all the betweenindividual variance in job satisfaction was removed when estimating the pooled within-individual parameters. In another model (Model 3), we regressed negative mood after work on job satisfaction to test Hypothesis $4 \mathrm{~b}$. The equations for both models are shown in the Appendix; the results of these analyses are summarized in Table 5. These results reveal that as hypothesized in Hypothesis $4 \mathrm{a}$, job satisfaction at work significantly predicted

\footnotetext{
${ }^{3}$ The model included a time index variable to control for possible time trends in job satisfaction and a lagged job satisfaction variable to account for the serial dependence in job satisfaction scores.

${ }^{4}$ We standardized these Level 1 regression coefficients by multiplying the estimated slope by the within-individual standard deviation of the independent variable divided by the within-individual standard deviation of the dependent variable.
} 
Table 3

HLM Estimates of the Effect of Concurrent Mood at Work on Job Satisfaction

\begin{tabular}{ccc}
\hline & \multicolumn{2}{c}{ Job satisfaction } \\
\cline { 2 - 3 } Estimate & $\beta$ & $\Delta R^{2}$ \\
\hline Intercept $\left(\beta_{0}\right)$ & $17.90^{* *}$ & .05 \\
Lagged job satisfaction $\left(\beta_{2}\right)$ & $0.12^{* *}$ & .48 \\
Unstandardized estimate & $0.12^{* *}$ & \\
Standardized estimate & & \\
Momentary affect at work & $0.15^{* *}$ & \\
Positive mood at work $\left(\beta_{3}\right)$ & $0.45^{* *}$ & \\
$\quad$ Unstandardized estimate & & \\
$\quad$ Standardized estimate & $-0.24 * *$ & \\
Negative mood at work $\left(\beta_{4}\right)$ & $-0.40^{* *}$ & \\
$\quad$ Unstandardized estimate & & \\
Standardized estimate &
\end{tabular}

Note. The model is based on 74 individuals and 1,055 data points (the number of momentary observations used in the analyses was decreased by the inclusion of lagged satisfaction scores because the scores were not lagged across individuals or across nonconsecutive observations, and these instances were treated as missing data). To account for eventual time trends in the data, regressions included a time index as a control variable; the effect of this index on job satisfaction was not significantly different from zero (standardized $\beta=.02 ; n s$ ). To form the lagged satisfaction variable, momentary job satisfaction scores were lagged by one period (for the 3:00 p.m. assessment, for example, the lagged variable score was the job satisfaction score reported by the respondents at 12:00 p.m.) All predictor scores were centered at the individuals' means to eliminate betweenindividual variance. $\beta=$ Level 1 regression coefficients (within-individual estimates); values presented in the table represent estimates for the final regression. $\Delta R^{2}=$ increase in variance explained by each regression block; all proportions of variance explained were computed as the proportional reduction in the Level 1 (within-individual) variance component of job satisfaction scores (see Hofmann, Griffin, \& Gavin, 2000). HLM = hierarchical linear modeling.

$* * p<.01$.

positive mood after work. Job satisfaction did predict negative mood after work negatively, but the results did not reach significance.

Hypothesis 5 predicted that the within-individual effect of job satisfaction on positive mood would be stronger for those high on trait PA and that the effect of job satisfaction on negative mood would be stronger for those high on trait NA. To test this hypothesis, in Model 4 and Model 5, we regressed individuals' slopes for predicting positive and negative mood with job satisfaction on their scores on trait affectivity (at Level 2 in the HLM analyses; see Appendix for model equations). As Table 5 shows, both of these hypotheses were supported. Trait affectivity does appear to affect individuals' sensitivity of their mood to job satisfaction. The significant moderating effects of trait affectivity are graphically illustrated in Figures 1 and 2. Figure 1 shows that the effect of job satisfaction on positive mood at home is stronger for those high on trait PA than for those low on trait PA. Figure 2 shows that the effect of job dissatisfaction (low job satisfaction) on negative mood at home is stronger for those high in trait NA than for those low in trait NA. We should note that because only one person provided the affectivity ratings for each participant, the affectivity scores perhaps do not represent the most reliable measure of participants' affectivity, which makes our between-individual results conservative.

Hypothesis 6 concerns the work-home mood spillover effect, and it specifically predicted that mood at work would predict mood at home, with positive (negative) mood at work predicting positive (negative) mood at home. Results of these analyses are provided in Table 6 (we do not present the equations for these models; they are very similar to those for Model 2 and Model 3). As the table shows, the results supported Hypothesis 6 in that positive mood at work predicted positive mood at home (assessed later that same day) and negative mood at work predicted negative mood at home (again, assessed later that day). Again, it is important to understand that these pooled within-individual estimates do not contain any effects due to differences between individuals. Because the estimates cannot include any between-individual effects, any concern that the relationships between mood across the work and home spheres may be due to individual differences in general mood can be safely eliminated. Though we did not formally hypothesize a home-work mood spillover effect, it is certainly possible that mood at home influenced mood at work. We investigated this possibility by means of multilevel analyses regressing mood at work on the previous day's mood at home. Whereas the homework spillover effect was not supported by the results of analyses at the day level, analyses at the momentary level revealed that the previous day's mood experienced at home did influence participants' mood experienced in the morning at work.

Table 4

HLM Estimates of the Effect of Mood at Work on Job Satisfaction

\begin{tabular}{lcccc}
\hline & \multicolumn{4}{c}{ Models predicting job satisfaction } \\
\cline { 2 - 5 } \multicolumn{1}{c}{ Estimate } & $\begin{array}{c}\text { At time } \\
t^{\mathrm{a}}\end{array}$ & $\begin{array}{c}\text { At time } \\
t+1^{\mathrm{b}}\end{array}$ & $\begin{array}{c}\text { At time } \\
t+2^{\mathrm{c}}\end{array}$ & $\begin{array}{c}\text { Next } \\
\text { day }\end{array}$ \\
\hline Intercept $\left(\beta_{0}\right)$ & $17.75^{* *}$ & $17.83^{* *}$ & $18.05^{* *}$ & $17.96^{* *}$ \\
$\begin{array}{l}\text { Positive mood at work }\left(\beta_{1}\right) \\
\text { Unstandardized estimate }\end{array}$ & $0.15^{* *}$ & 0.00 & 0.01 & -0.02 \\
$\quad$ Standardized estimate & $0.45^{* *}$ & 0.01 & 0.03 & -0.06 \\
Negative mood at work $\left(\beta_{2}\right)$ & & & & \\
$\quad$ Unstandardized estimate & $-0.24^{* *}$ & $-0.09^{* *}$ & 0.04 & 0.01 \\
$\quad$ Standardized estimate & $-0.40^{* *}$ & $-0.15^{* *}$ & 0.06 & 0.01 \\
$\Delta R^{2}$ & 0.48 & 0.03 & 0.03 & 0.11 \\
\hline
\end{tabular}

Note. To account for autocorrelated residuals and for eventual time trends that may have been present in the data, all models included lagged job satisfaction and a time index as control variables. To form the lagged satisfaction variable, momentary job satisfaction scores were lagged by one period. All predictor scores were centered at the individuals' means to eliminate between-individual variance. $\beta=$ Level 1 regression coefficients (within-individual estimates). $\Delta R^{2}=$ the variance explained by the two mood variables over and above the variance explained by the control variables (the proportions were computed as the proportional reduction in the Level 1 variance component of job satisfaction scores; see Hofmann, Griffin, \& Gavin, 2000). HLM = hierarchical linear modeling.

${ }^{\text {a }}$ Momentary job satisfaction measured concurrently with mood. This model is based on 74 individuals and 1,055 data points. ${ }^{\mathrm{b}}$ Momentary job satisfaction measured one time period after mood. This model is based on 70 individuals and 642 data points. ${ }^{\mathrm{c}}$ Momentary job satisfaction measured two time periods after mood. This model is based on 63 individuals and 266 data points. ${ }^{\mathrm{d}}$ Momentary job satisfaction measured next day. This model is based on 67 individuals and 255 data points. $* * p<.01$. 
Table 5

HLM Estimates of the Effect of Job Satisfaction on Mood After Work

\begin{tabular}{lcc}
\hline \multicolumn{1}{c}{ Estimate } & $\begin{array}{c}\text { Positive mood } \\
\text { after work }\end{array}$ & $\begin{array}{c}\text { Negative mood } \\
\text { after work }\end{array}$ \\
\hline Intercept $\left(\beta_{0}\right)$ & $22.65 * *$ & $4.06 * *$ \\
Level 1: job satisfaction $\left(\beta_{1}\right)$ & $0.63 * *$ & -0.24 \\
$\quad$ Unstandardized estimate & $0.17 * *$ & -0.11 \\
$\quad$ Standardized estimate & 0.05 & 0.22 \\
$\Delta R^{2}$ & & $-0.05 * *$ \\
Level 2: moderating effects $\left(\gamma_{11}\right)$ & & $-0.22 * *$ \\
Trait-negative affectivity & & \\
$\quad$ Unstandardized estimate & & \\
Standardized estimate & & \\
Trait-positive affectivity & $0.04 * *$ & \\
$\quad$ Unstandardized estimate & $0.12^{* *}$ & \\
Standardized estimate & & \\
\hline
\end{tabular}

Note. The models were based on 53 individuals and 372 data points (daily averages of work and home ratings). Both models included a day index to control for possible time trends. The Level 1 predictor scores (i.e., state job satisfaction) were centered at the individuals' means to eliminate between-individual variance. $\beta=$ Level 1 regression coefficients (withinindividual estimates) for predicting home moods with work job satisfaction. $\Delta R^{2}=$ the variance explained by job satisfaction over and above the variance explained by the control variable (the proportions were computed as the proportional reduction in the Level 1 variance component of job satisfaction scores; see Hofmann, Griffin, \& Gavin, 2000). The total residual variance did not decrease on introducing the cross-level moderator effect in the mixed model (the within-individual residual variances did decrease but the between-individual variance slightly increased; see Snijders \& Bosker, 1999, for a treatment of negative $R^{2}$ values in multilevel modeling and alternative formulas). Trait-positive and trait-negative affectivity were measured with significant-other ratings. The standardized estimates for the moderating effects show the increase in the Level 1 regression coefficient for predicting positive or negative mood at home with job satisfaction, in standardized points, that corresponds to one standard deviation increase in the trait-positive or trait-negative affectivity scores. HLM $=$ hierarchical linear modeling.

$* * p<.01$.

\section{Discussion}

Fox and Spector (2002) noted that in psychology in general and in job satisfaction research in particular, cognition has been emphasized more than emotions, and when emotions have been considered, the focus generally has been on emotional traits rather than on emotional states or moods. Although a fresh focus on affect in job satisfaction research is underway, this research still is in its infancy (Brief \& Weiss, 2002). There is an extensive literature linking trait affectivity to job satisfaction (see Connolly \& Viswesvaran, 2000, for a review). However, little research has linked transient measures of mood at work to job satisfaction with a dynamic design that is capably of fully capturing these relationships.

Weiss et al. (1999) supported the importance of studying dynamic mood states rather than aggregated reports of mood. Ilies and Judge (2002) found that traditional between-subjects designs missed more than one third of the variance in job satisfaction. Fisher (2002) found that both positive and negative affect, measured dynamically, contribute to job satisfaction. The present study seeks to extend further this line of research. Furthermore, we followed George's (1989) advice and considered employees' mood both at work and off work in investigating the dynamic relationship between mood and job satisfaction.

We believe that this study contributes to the mood and job satisfaction literature in general and to the emergent literature on the dynamic interrelationships between personality, mood, and job satisfaction in particular, in four specific areas. Within the two broad aims of this study - to investigate the dynamic relationship between mood and job satisfaction and the spillover effects from work to home- - these specific areas are the following: (a) mood as a mediator of the trait affectivity-job satisfaction relationship, (b) mutual influences of mood and job satisfaction on each other, including the stability of these effects, (c) spillover effects of work mood and job satisfaction to mood in off-work settings, and (d) the

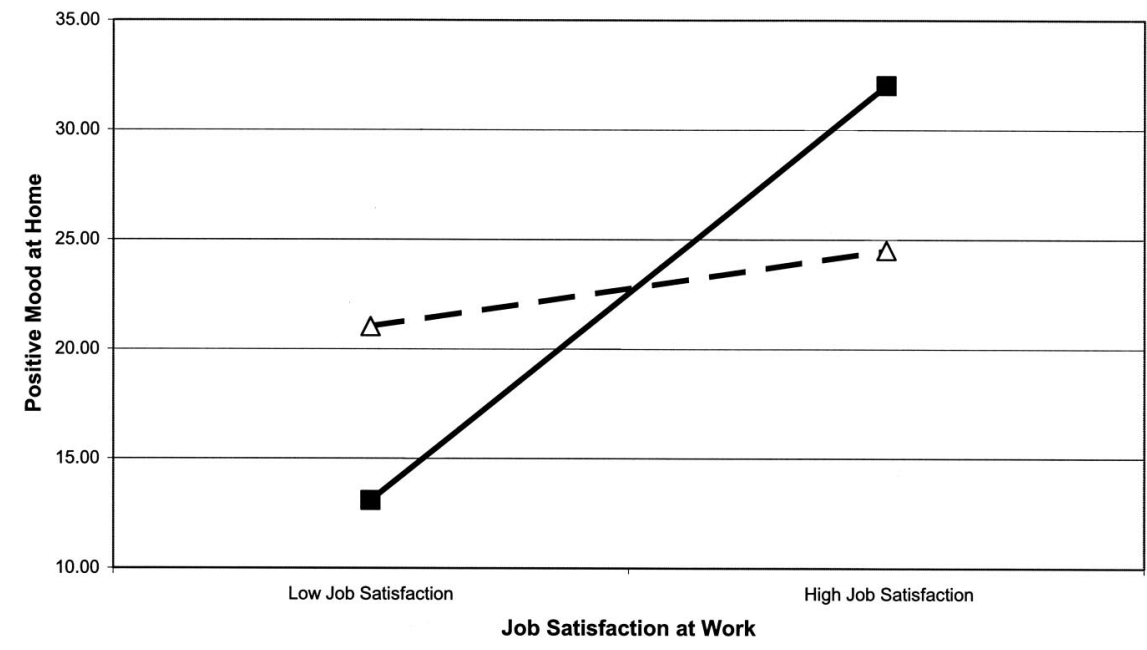

Figure 1. The moderating effect of trait-positive affectivity on the relationship between job satisfaction at work and positive mood at home. Dashed line represents 1 standard deviation below the mean on positive affectivity; solid line represents 1 standard deviation above the mean on positive affectivity. 


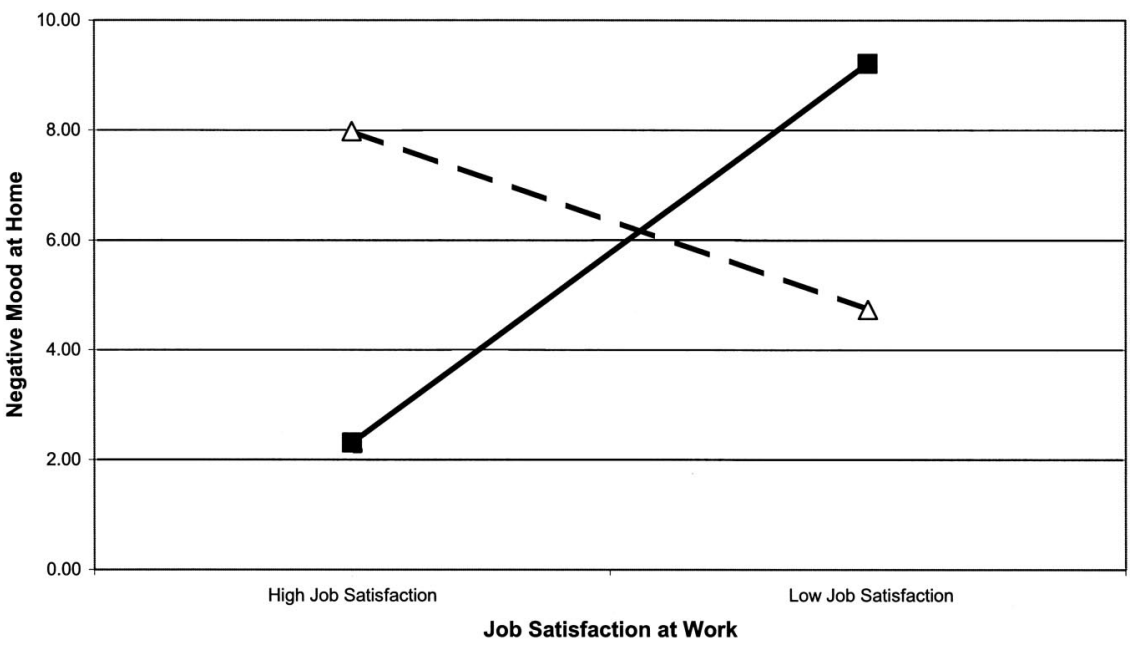

Figure 2. The moderating effect of trait-negative affectivity on the relationship between job satisfaction at work and negative mood at home. Dashed line represents 1 standard deviation below the mean on negative affectivity; solid line represents 1 standard deviation above the mean on negative affectivity.

moderating role of personality. Below we discuss these areas of contribution.

\section{Mood as a Mediator of the Trait Affectivity-Job Satisfaction Relationship}

Following Brief (1998) and Weiss (2002), we investigated whether mood mediates the trait affectivity-job satisfaction relationship. The results suggest that the experience of affect at work is one mechanism that explains why people's affective traits are associated with their reports of job satisfaction. But the mediation effect was only partial, which suggests that other mechanisms may also mediate the trait affectivity-job satisfaction relationship. It may be the case that affective traits also influence cognitive interpretations of work stimuli. That is, affective traits may influence people's cognitive assessments of their job situations (perhaps both directly and indirectly through mood). Because trait PA

Table 6

HLM Estimates of the Effect of Mood at Work on Mood at Home

\begin{tabular}{lcc}
\hline \multicolumn{1}{c}{ Mood at work } & Positive & Negative \\
\hline Intercept $\left(\beta_{1}\right)$ & $22.66^{* *}$ & $4.04^{* *}$ \\
Positive mood at work $\left(\beta_{1}\right)$ & $0.25^{* *}$ & -0.02 \\
$\quad$ Unstandardized estimate & $0.20^{* *}$ & -0.03 \\
$\quad$ Standardized estimate & -0.19 & \\
Negative mood at work $\left(\beta_{2}\right)$ & -0.10 & $0.41^{* *}$ \\
$\quad$ Unstandardized estimate & 0.11 & $0.34^{* *}$ \\
$\quad$ Standardized estimate & $R^{2}$ & 0.45 \\
\hline
\end{tabular}

Note. The models were based on 67 individuals and 396 data points (daily averages of work and home ratings). The models included a day index to control for possible time trends. The Level 1 predictor scores (i.e., state-positive and state-negative mood at work) were centered at the individuals' means to eliminate between-individual variance. HLM = hierarchical linear modeling.

$* * p<.01$ was more strongly related to job satisfaction than was trait NAboth before and after controlling for state PA at work-trait PA may play a stronger cognitive role in evaluations of job satisfaction than trait NA. Such an interpretation is consistent with theories and findings in basic attitude research.

Specifically, attitude research suggests that individuals in whom positive mood has been induced engage in different cognitive processes than do those in whom no such mood has been induced Positive mood appears to reduce systematic processing of information, such that individuals with positive mood are more susceptible to heuristic cues (Worth \& Mackie, 1987). Reliance on these heuristic cues may be a means of maintaining positive moods; to invest effort in obtaining and processing detailed information (as opposed to relying on heuristics) might lead to the dissipation of the positive mood (one might learn something that would run counter to the mood; Eagley \& Chaiken, 1993). Moreover, a positive mood might optimistically bias the processing of information (Shaller \& Cialdini, 1990), which would also reinforce maintenance of a positive mood. It is interesting that the link between negative affect and cognitive processes is less studied and the results are more equivocal (Eagley \& Chaiken, 1993). Our study reveals that both trait PA and trait NA and positive and negative mood generally are related to job satisfaction, though the effects for mood dissipate rather quickly, especially for positive mood.

What we are arguing is that if affectivity (trait PA and trait NA) leads to mood (state PA and state NA) and if mood leads to differential processing of job information, then these cognitive processes may explain further the effect of trait affectivity on job satisfaction. Given our findings and our interpretation of their possible meaning, the effects of affective traits on job cognitions should be investigated in future research. Thus, showing that dynamic mood mediates some but not all of the effect of trait affectivity on job satisfaction responds to calls to better understand the processes by which affective traits influence job satisfaction (Brief, 1998; Brief \& Weiss, 2002) while also suggesting future research that would include cognitive processes. 


\section{Mutual Influences Between Mood and Job Satisfaction}

Previous research has assumed that the relationship between state affect (mood) and job satisfaction represents the effect of mood on job satisfaction. Indeed, the results in Table 3 reveal that both positive mood and negative mood have significant concurrent effects on job satisfaction (these effects are short-lived, as we found no evidence of an effect of current mood on the next day's job satisfaction-see Table 4). However, the results in Table 5 show that job satisfaction assessed at work, in turn, has significant effects on positive (but not negative) mood after work. Thus, a significant contribution of this study is to show that mood and job satisfaction appear to have mutual effects on one another-especially in the case of positive mood. Thus, not only can affect be considered as a distinct influence on or as a part of job satisfaction (Brief \& Weiss, 2002), but it can also be viewed as a consequence of job satisfaction. By investigating whether job satisfaction influences employees' mood measured later in the day, we examined whether mood can also be viewed as a reaction or response to job satisfaction. The results suggest that such view is appropriate.

We should note that the dynamic nature of our data allowed us to investigate these two distinct causal links: from mood to job satisfaction, and from job satisfaction to mood, in a multilevel modeling framework. These analyses are appropriate because (a) the temporal ordering of the variables was correct and (b) we conducted regressions strictly within individuals (by eliminating the between-individual variance in the predictor scores). In contrast, cross-sectional analyses, even when they include a longitudinal component, cannot separate within- and between-individual effects, thus making the interpretation of such results more problematic.

\section{Spillover Effects}

Although the work-family literature has made substantial progress in the decade since Zedeck's (1992) appraisal of the literature, linking mechanisms that explain the relationship between work and family roles are sorely lacking in the literature (Edwards \& Rothbard, 2000; Zedeck, 1992). Whereas depletion is a dominant theme in the work-family literature, where it is assumed that work and family roles detract from one another (Rothbard, 2001), the results presented here suggest that affective spillover occurs between the domains. Specifically, the results show that how employees feel about their job influences the moods they experience at home. In addition, the results indicate that mood at work also spills over outside the work area in that it influences mood at home. The within-individual nature of the analyses gives these results a precise interpretation. That is, the influence of job satisfaction on mood at home within individuals, for example, means that the affective states experienced by employees at home vary from day to day in synchrony with the feelings of satisfaction that they experienced at work earlier in the day. Because all the possible effects of differences across individuals were controlled in the analyses of the time-sampled data, the explanation that individual differences are responsible for the observed pattern of relationships between mood and job satisfaction across time was eliminated.

The findings contribute to the work-family literature by clarifying spillover processes (Lambert, 1990) or linking mechanisms
(Edwards \& Rothbard, 2000) that explain ways in which the work and family boundaries are permeable. Lambert (1990) noted that spillover effects can be positive or negative. In the area of mood and job satisfaction, it appears that the positive spillover effects are more important. For the relationship of mood to job satisfaction, it appears the spillover effects are ephemeral—only negative mood had more than a concurrent effect on job satisfaction (see Table 4). Furthermore, job satisfaction did impact positive mood at home (see Table 5). Finally, there were moderately strong spillover effects from mood at work to mood at home in that positive mood and negative mood at work impact positive mood and negative mood at home, respectively (see Table 6). Although the spillover model has garnered considerable support in the literature (Lambert, 1990), our results suggest a new avenue of support for the model in terms of affective processes.

\section{The Moderating Role of Personality}

An important area of research in the past decade has been the investigation of trait congruency effects whereby extraverted or high-PA individuals are more responsive to positive stimuli and neurotic or high-NA individuals are more responsive to negative stimuli (Rusting \& Larsen, 1999). Past research has investigated these effects in terms of sensitivity to mood induction (Rusting \& Larsen, 1999), cognitive processing of information (Rusting \& DeHart, 2000), and sensitivity to rewards or punishments (Stewart, 1996). The cross-level moderator analyses presented here (see Table 5) suggest a new way of investigating the trait congruency connection between personal characteristics and sensitivity to rewards and punishments - examining the impact of trait PA and trait NA on the effect of job satisfaction at work on positive and negative mood after work. These results are important because they show not only that dispositions have direct effects on mood and job satisfaction but that they also influence how mood and job satisfaction are interrelated across time. Specifically, employees' standing on measures of affective traits impact the extent to which their job satisfaction influences their mood after work. In this way, the results provide further support for trait congruency effects. Trait PA amplifies the effect of individuals' job satisfaction on their positive mood after work, whereas trait NA amplifies the effect of dissatisfaction on negative mood.

\section{Limitations and Strengths}

One limitation of this study is sample size. Although the sample size was 74 , it was reduced to 52-55 when the between-subjects and within-subjects data were combined and missing data were taken into account. However, in the other two studies on the topic, the sample sizes were approximately half this size $(N=27$ in Ilies \& Judge, 2002; $N=24$ in Weiss et al., 1999). Given the intensity of the data collection efforts, with multiple observations per participant being required daily over the period of 2 weeks, it is difficult to collect such data with large numbers of participants. Furthermore, because HLM affords more power than traditional between-subjects techniques, the moderate sample sizes used in the analysis are less of a concern. With respect to our test of the mediation hypothesis (Hypothesis 1), because this test was based exclusively on between-individual variance, the low power associated with the small sample size means that further replication is 
needed before drawing firm conclusions on the mediating role of state affect on the trait affectivity-job satisfaction relationship.

The design of this study also has strengths. One such strength is that data were collected at two different levels (dispositional and experience-sampled data), from two sources (self and significant other), and in two contexts (at work and at home). In addition, the use of composites formed by multiple time-sampled reports of mood and job satisfaction in cross-sectional analyses controlled for the effect of transient errors on the reported scores (i.e., for cross-sectional analyses temporal variations were treated as transient errors), which minimized the effects of measurement error on the cross-sectional estimates presented here.

\section{Implications and Future Research}

Our results have both practical implications and implications for researchers interested in studying job attitudes and mood at work and at home. For employees and employers, there is value in understanding that the affective experiences at work can affect both job satisfaction and mood at work, both of which have spillover effects to mood at home. In this way, the results extend affective events theory (Weiss \& Cropanzano, 1996), which maintains that "affective experiences at work influence overall judgments about satisfaction with one's job" (Weiss \& Cropanzano, 1996, p. 46). Our results suggest that the aftermath of affective events likely reaches to the home life as well. If employers care about the work-family balance achieved by their employees, and there is reason to believe that they should (Milliken, Martins, \& Morgan, 1998), then employers can contribute to positive moods in both work and nonwork domains through the way they treat employees. For example, research shows that treating individuals fairly affects discrete emotional reactions (Weiss, Suckow, \& Cropanzano, 1999). Putting in place fair processes may not only raise employee satisfaction, it may have residual benefits in terms of affective reactions away from work. For employees, that the consequences of having a satisfying (or dissatisfying) job spill over onto one's mood at home provides further evidence for the importance of being in a satisfying job. When one considers the contagious effect of emotions on others (Neumann \& Strack, 2000), this spillover effect may be amplified even further at home.

In addition to practical implications, the results suggest several promising avenues for future research. Although affective events theory (Weiss \& Cropanzano, 1996) has been cast in terms of work events and how these events affect work affect and attitudes, the theory certainly could be broadened to include the home domain. In the theory, work events produce affective reactions which in turn lead to job attitudes. In future research, the theory could be broadened to include events that happen at home and the relationship of the resulting affective reactions to work affect and job attitudes. Similarly, the theory could broaden the study of work events to analyze the effect of these events (and the affective reactions) to affective processes at home. Stone (1987), for example, analyzed the effect of daily life events on mood, and Grandey, Tam, and Brauburger (2002) analyzed the relationship between work affective events and affective reactions. These separate areas of research could be brought together and expand the scope and implications of affective events theory.

Another area for future research is to test the elements of the models presented by Edwards and Rothbard (2000) on the work- family interface. These authors propose several models that hypothesize the interrelationships among role performance, rewards, and mood in both work and family roles. An important extension of the results presented in this article would be not only to replicate the results observed here but also to consider behavior in work and family roles as well as the rewards each of these roles provides. Trait congruency effects could be investigated in which the effect of work and family rewards on work and family mood, respectively, are moderated by trait PA in addition to the moderation effects observed here.

\section{Conclusion}

We believe that this article contributes to the literature on personality, mood, and job satisfaction and that our results have important implications for studying work-family conflict through the investigation of job satisfaction and mood spillover effects from work. First, we have shown that state mood influences state job satisfaction, and that the effect declines rapidly with the passage of time. Second, we found that employees' satisfaction with their job, measured at work, influences the affective states experienced by employees at home, and the magnitudes of these influences vary according to employees' trait affectivity. Third, the present results show that mood does spill over outside the work environment in that the affective states experienced at work influenced mood measured later in the day, at home. Jointly, the results presented here enhance our understanding of the psychological mechanisms through which individuals' mood and job satisfaction are interconnected across work and off-work spheres and across time, and of the ways in which stable dispositions influence these mechanisms.

\section{References}

Altmann, E. M., \& Gray, W. D. (2002). Forgetting to remember: The functional relationship of decay and interference. Psychological Science, 13, 27-33.

Bower, G. J. (1981). Mood and memory. American Psychologist, 36, 129-148.

Brayfield, A. H., \& Rothe, H. F. (1951). An index of job satisfaction. Journal of Applied Psychology, 35, 307-311.

Brief, A. P. (1998). Attitudes in and around organizations. Thousand Oaks, CA: Sage.

Brief, A. P., \& Weiss, H. M. (2002). Organizational behavior: Affect in the workplace. Annual Review of Psychology, 53, 279-307.

Byrk, A. S., \& Raudenbush, S. W. (1992). Hierarchical linear models: Applications and data analysis methods. Thousand Oaks, CA: Sage.

Byrk, A. S., Raudenbush, S. W., \& Congdon, R. T., Jr. (2000). HLM 5 for windows. Chicago: Scientific Software International.

Connolly, J. J., \& Viswesvaran, C. (2000). The role of affectivity in job satisfaction: A meta-analysis. Personality and Individual Differences, 29, 265-281.

Damasio, A. R. (2001). Emotion and the human brain. In A. R. Damasio \& A. Harrington (Eds.), Unity of knowledge: The convergence of natural and human science (pp. 101-106). New York: New York Academy of Sciences.

Eagley, A. H., \& Chaiken, S. (1993). The psychology of attitudes. Fort Worth, TX: Harcourt.

Edwards, J. R., \& Rothbard, N. P. (2000). Mechanisms linking work and family: Specifying the relationships between work and family constructs. Academy of Management Review, 25, 178-199. 
Fishbein, M., \& Ajzen, I. (1975). Belief, attitude, intention, and behavior. Reading, MA: Addison Wesley.

Fisher, C. D. (2002). Antecedents and consequences of real-time affective reactions at work. Motivation and Emotion, 26, 3-30.

Fox, S., \& Spector, P. E. (2002). Emotions in the workplace-The neglected side of organizational life: Introduction. Human Resource Management Review, 12, 167-171.

George, J. M. (1989). Mood and absence. Journal of Applied Psychology, 74, 317-324

Grandey, A. A., Tam, A. P., \& Brauburger, A. L. (2002). Affective states and traits in the workplace: Diary and survey data from young workers. Motivation and Emotion, 26, 31-55.

Gray, J. A. (1990). Brain systems that mediate both emotion and cognition. Motivation and Emotion, 4, 269-288.

Hofmann, D. A., Griffin, M. A., \& Gavin, M. B. (2000). The application of hierarchical linear modeling to organizational research. In K. Klein \& S. Kozlowski (Eds.), Multilevel theory, research, and methods in organizations: Foundations, extensions, and new directions (pp. 467-511). San Francisco: Jossey-Bass.

Hulin, C. L. (1991). Adaptation, persistence, and commitment in organizations. In M. D. Dunnette \& L. M. Hough (Eds.), Handbook of industrial and organizational psychology (2nd ed., Vol. 2, pp. 445-505). Palo Alto, CA: Consulting Psychologists Press.

Hulin, C. L. (2002). Lessons from industrial and organizational psychology. In J. M. Brett \& F. Drasgow (Eds.), The psychology of work: Theoretically based empirical research (pp. 3-22). Mahwah, NJ: Erlbaum.

Hulin, C. L., Henry, R. A., \& Noon, S. L. (1990). Adding a dimension: Time as a factor in the generalizability of predictive relationships. Psychological Bulletin, 107, 328-340.

Ilies, R., \& Judge, T. A. (2002). Understanding the dynamic relationship between personality, mood, and job satisfaction: A field experiencesampling study. Organizational Behavior and Human Decision Processes, 89, 1119-1139.

Isen, A. M., \& Baron, R. A. (1991). Positive affect as a factor in organizational behavior. Research in Organizational Behavior, 13, 1-53.

Izard, C. E. (1991). The psychology of emotions. New York: Plenum Press.

Kuhn, T. S. (1970). The structure of scientific revolutions (2nd ed.). Chicago: University of Chicago Press.

Lambert, S. J. (1990). Processes linking work and family: A critical review and research agenda. Human Relations, 43, 239-257.

Larsen, R. J., \& Ketelaar, T. (1989). Extraversion, neuroticism, and susceptibility to positive and negative mood induction procedures. Personality and Individual Differences, 10, 1221-1228.

Locke, E. A. (1969). What is job satisfaction? Organizational Behavior and Human Performance, 4, 309-336.

Locke, E. A. (1976). The nature and causes of job satisfaction. In M. D. Dunnette (Ed.), Handbook of industrial and organizational psychology (pp. 1297-1349). Chicago: Rand McNally.

Matthews, G., \& Gilliland, K. (1999). The personality theories of H. J. Eysenck and J. A. Gray: A comparative review. Personality and Individual Differences, 26, 583-626.

Milliken, F. J., Martins, L. L., \& Morgan, H. (1998). Explaining organizational responsiveness to work-family issues: The role of human resource executives as issue interpreters. Academy of Management Journal, 41, 580-592.

Neumann, R., \& Strack, F. (2000). "Mood contagion": The automatic transfer of mood between persons. Journal of Personality and Social Psychology, 79, 211-223.

Parasuraman, S., \& Greenhaus, J. H. (2002). Toward reducing some critical gaps in work-family research. Human Resource Management Review, 12, 299-312.
Rothbard, N. P. (2001). Enriching or depleting? The dynamics of engagement in work and family roles. Administrative Science Quarterly, 46, $655-684$.

Rusting, C. L., \& DeHart, T. (2000). Retrieving positive memories to regulate negative mood: Consequences for mood-congruent memory. Journal of Personality and Social Psychology, 78, 737-752.

Rusting, C. L., \& Larsen, R. J. (1999). Clarifying Gray's theory of personality: A response to Pickering, Corr, and Gray. Personality and Individual Differences, 26, 167-172.

Shaller, M., \& Cialdini, R. B. (1990). Happiness, sadness, and helping: A motivational integration. In E. T. Higgins \& R. M. Sorrentino (Eds.), Handbook of motivation and cognition (Vol. 2, pp. 265-296). New York: Guilford Press.

Snijders, T., \& Bosker, R. (1999). Multilevel Analysis: An introduction to basic and advanced multilevel modeling. London: Sage.

Spector, P. E. (1997). Job satisfaction: Application, assessment, causes, and consequences. Thousand Oaks, CA: Sage.

Stewart, G. L. (1996). Reward structure as a moderator of the relationship between extraversion and sales performance. Journal of Applied Psychology, 81, 619-627.

Stone, A. A. (1987). Event content in a daily survey is differentially associated with concurrent mood. Journal of Personality and Social Psychology, 52, 56-58.

Sumer, H. C., \& Knight, P. A. (2001). How do people with different attachment styles balance work and family? A personality perspective on work-family linkage. Journal of Applied Psychology, 86, 653-663.

Watson, D. (2000). Mood and temperament. New York: Guilford Press.

Watson, D., Clark, L. A., \& Tellegen, A. (1988). Development and validation of brief measures of positive and negative affect: The PANAS scales. Journal of Personality and Social Psychology, 54, 1063-1070.

Watson, D., \& Slack, A. K. (1993). General factors of affective temperament and their relation to job satisfaction over time. Organizational Behavior and Human Decision Processes, 54, 181-202.

Watson, D., Wiese, D., Vaidya, J., \& Tellegen, A. (1999). The two general activation systems of affect: Structural findings, evolutionary considerations, and psychobiological evidence. Journal of Personality and Social Psychology, 76, 805-819.

Weiss, H. M. (2002). Deconstructing job satisfaction: Separating evaluations, beliefs and affective experiences. Human Resource Management Review, 12, 173-194.

Weiss, H. M., \& Cropanzano, R. (1996). Affective events theory: A theoretical discussion of the structure, causes and consequences of affective experiences at work. Research in Organizational Behavior, 18, $1-74$.

Weiss, H. M., Nicholas, J. P., \& Daus, C. S. (1999). An examination of the joint effects of affective experiences and job beliefs on job satisfaction and variations in affective experiences over time. Organizational Behavior and Human Decision Processes, 78, 1-24.

Weiss, H. M. Suckow, K., \& Cropanzano, R. (1999). Effects of justice on discrete emotions. Journal of Applied Psychology, 84, 786-794.

Wheeler, L., \& Reis, H. T. (1991). Self-recording of everyday life events: Origins, types, and uses. Journal of Personality, 59, 339-354.

Williamson, G. M., \& Clark, M. S. (1989). Providing help and desired relationship type as determinants of changes in moods and selfevaluations. Journal of Personality and Social Psychology, 56, 722-734.

Worth, L. T., \& Mackie, D. M. (1987). Cognitive mediation of positive affect in persuasion. Social Cognition, 5, 76-94.

Wright, T. A., Bennett, K. K., \& Dun, T. (1999). Life and job satisfaction. Psychological Reports, 84, 1025-1028.

Zedeck, S. (Ed.). (1992). Work, families, and organizations. San Francisco: Jossey-Bass. 


\section{Appendix}

\section{Equations for HLM Models}

Model 1

Level 1 (Within Individuals; Momentary Ratings):

Job Satisfaction at Work $_{\mathrm{ij}}=\beta_{0 \mathrm{j}}+\beta_{1 \mathrm{j}}\left(\right.$ Positive Mood at Work $\left._{\mathrm{ij}}\right)+\beta_{2 \mathrm{j}}$ (Negative Mood at Work $_{\mathrm{ij}}$ ) $+\mathrm{r}_{\mathrm{ij}}$

Level 2 (Between Individuals):

$$
\begin{aligned}
& \beta_{0 \mathrm{j}}=\gamma_{00}+\mathrm{U}_{0 \mathrm{j}} \\
& \beta_{1 \mathrm{j}}=\gamma_{10}+\mathrm{U}_{1 \mathrm{j}} \\
& \beta_{2 \mathrm{j}}=\gamma_{20}+\mathrm{U}_{2 \mathrm{j}}
\end{aligned}
$$

Where:

$$
\begin{aligned}
\beta_{0 \mathrm{j}}= & \text { Level } 1 \text { intercept } \\
\beta_{1 \mathrm{j}}= & \text { Individuals' slopes for predicting momentary Job Satisfaction } \\
& \text { at Work with concurrent Positive Mood at Work } \\
\beta_{2 \mathrm{j}}= & \text { Individuals' slopes for predicting momentary Job Satisfaction } \\
& \text { at Work with concurrent Negative Mood at Work } \\
\gamma_{00}= & \text { Grand mean of Job Satisfaction at Work scores, after the } \\
& \text { within-individual effect of concurrent mood was accounted } \\
& \text { for } \\
\gamma_{10}= & \begin{array}{l}
\text { Pooled slope for predicting momentary Job Satisfaction at } \\
\text { Work with concurrent Positive Mood at Work }
\end{array} \\
\gamma_{20}= & \text { Pooled slope for predicting momentary Job Satisfaction at } \\
& \text { Work with concurrent Negative Mood at Work }
\end{aligned}
$$

\section{Model 2}

Level 1 (Within Individuals; Daily Averages):

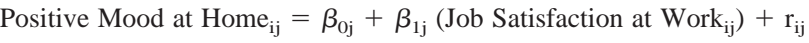

Level 2 (Between Individuals):

$$
\begin{aligned}
& \beta_{0 \mathrm{j}}=\gamma_{00}+\mathrm{U}_{0 \mathrm{j}} \\
& \beta_{1 \mathrm{j}}=\gamma_{10}+\mathrm{U}_{1 \mathrm{j}}
\end{aligned}
$$

Where:

$$
\begin{aligned}
\beta_{1 \mathrm{j}}= & \text { Individuals' slopes for predicting Positive Mood at Home } \\
& \text { with Job Satisfaction at Work }
\end{aligned}
$$

Model 3

Level 1 (Within Individuals; Daily Averages):

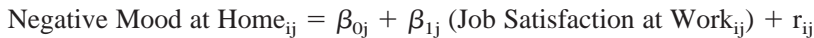

Level 2 (Between Individuals):

$$
\begin{aligned}
& \beta_{0 \mathrm{j}}=\gamma_{00}+\mathrm{U}_{0 \mathrm{j}} \\
& \beta_{1 \mathrm{j}}=\gamma_{10}+\mathrm{U}_{1 \mathrm{j}}
\end{aligned}
$$

Where:

$$
\begin{aligned}
\beta_{1 \mathrm{j}}= & \text { Individuals' slopes for predicting Negative Mood at Home } \\
& \text { with Job Satisfaction at Work } \\
\gamma_{10}= & \text { Pooled slope for predicting Negative Mood at Home with Job }
\end{aligned}
$$
Satisfaction at Work

Model 4

Level 1 (Within Individuals; Daily Averages):

Positive Mood at Home $\mathrm{ij}_{\mathrm{ij}}=\beta_{0 \mathrm{j}}+\beta_{1 \mathrm{j}}\left(\right.$ Job Satisfaction at Work $\left.\mathrm{ij}_{\mathrm{j}}\right)+\mathrm{r}_{\mathrm{i}}$

Level 2 (Between Individuals):

$\beta_{0 \mathrm{j}}=\gamma_{00}+\gamma_{01}$ (Positive Affectivity) $+\mathrm{U}_{0 \mathrm{j}}$

$\beta_{1 \mathrm{j}}=\gamma_{10}+\gamma_{02}$ (Positive Affectivity) $\mathrm{U}_{1 \mathrm{j}}$

Where:

$$
\begin{aligned}
\beta_{1 \mathrm{j}}= & \text { Individuals' slopes for predicting Positive Mood at Home with } \\
& \text { Job Satisfaction at Work } \\
\gamma_{01}= & \text { Level } 2 \text { slope for predicting } \beta_{0 \mathrm{j}} \text { with Positive Affectivity } \\
\gamma_{11}= & \text { Level } 2 \text { slope for predicting the Level } 1 \text { slope with Positive } \\
& \text { Affectivity }
\end{aligned}
$$

\section{Model 5}

Level 1 (Within Individuals; Daily Averages):

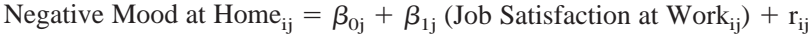

Level 2 (Between Individuals):

$\beta_{0 \mathrm{j}}=\gamma_{00}+\gamma_{01}$ (Negative Affectivity) $+\mathrm{U}_{0 \mathrm{j}}$
$\beta_{1 \mathrm{j}}=\gamma_{10}+\gamma_{11}$ (Negative Affectivity) $+\mathrm{U}_{1 \mathrm{j}}$

Where:

$\beta_{1 \mathrm{j}}=$ Individuals' slopes for predicting Negative Mood at Home with Job Satisfaction at Work

$\gamma_{01}=$ Level 2 slope for predicting $\beta_{0 \mathrm{j}}$ with Negative Affectivity

$\gamma_{11}=$ Level 2 slope for predicting the Level 1 slope with Negative Affectivity

Received September 3, 2002

Revision received September 3, 2003

Accepted September 16, 2003 
Copyright of Journal of Applied Psychology is the property of American Psychological Association and its content may not be copied or emailed to multiple sites or posted to a listserv without the copyright holder's express written permission. However, users may print, download, or email articles for individual use. 